\title{
$\mathrm{DC}$ 마그네트론 스퍼터링 방법을 이용하여 증착한 IGZO 박막트랜지스터의 특성
}

\author{
김성연 · 명재민 ${ }^{\dagger}$ \\ 연세대학교 신소재공학부

\section{Characteristics of IGZO Thin Film Transistor Deposited by DC Magnetron Sputtering}

\author{
Sungyeon Kim and Jae-Min Myoung ${ }^{\dagger}$ \\ Information and Electronic Materials Research Laboratory, \\ Department of Materials Science and Engineering, Yonsei University
}

(2008년 12월 4일 접수 : 2008년 12월 24일 최종수정 : 2008년 12월 30일 채택)

\begin{abstract}
Indium Gallium Zinc Oxide (IGZO) thin films were deposited onto $300 \mathrm{~nm}$-thick oxidized Si substrates and glass substrates by direct current (DC) magnetron sputtering of IGZO targets at room temperature. FESEM and XRD analyses indicate that non-annealed and annealed IGZO thin films exhibit an amorphous structure. To investigate the effect of an annealing treatment, the films were thermally treated at $300{ }^{\circ} \mathrm{C}$ for $1 \mathrm{hr}$ in air. The IGZO TFTs structure was a bottom-gate type in which electrodes were deposited by the DC magnetron sputtering of $\mathrm{Ti}$ and $\mathrm{Au}$ targets at room temperature. The non-annealed and annealed IGZO TFTs exhibit an $\mathrm{I}_{\text {on }} / \mathrm{I}_{\text {off }}$ ratio of more than $10^{5}$. The saturation mobility and threshold voltage of nonannealed IGZO TFTs was $4.92 \times 10^{-1} \mathrm{~cm}^{2} / \mathrm{V} \cdot \mathrm{s}$ and $1.46 \mathrm{~V}$, respectively, whereas these values for the annealed TFTs were $1.49 \times 10^{-1} \mathrm{~cm}^{2} / \mathrm{V} \cdot \mathrm{s}$ and $15.43 \mathrm{~V}$, respectively. It is believed that an increase in the surface roughness after an annealing treatment degrades the quality of the device. The transmittances of the IGZO thin films were approximately $80 \%$. These results demonstrate that IGZO thin films are suitable for use as transparent thin film transistors (TTFTs).
\end{abstract}

Key words IGZO, sputtering, transparent thin film transistors (TTFT)

\section{1. 서 론}

전자재료는 지금까지 주로 $\mathrm{Si}$ 기반의 기판에서 구현되 며 발전하여 왔다. 그러나 최근 평판 디스플레이 산업 등 새로운 응용분야가 나타나면서 기존의 $\mathrm{Si}$ 기판에서 기반 의 소자가 감당할 수 없는 응용분야까지 그 범위가 확 장되었다. 투명박막 트랜지스터는 정보 인식, 정보 처리, 정보 표시의 기능을 투명한 전자기기로 구현함으로써 기 존 전자기기가 가지고 있는 공간적, 시각적 제약을 해소 하는 것이 가능하다. 이러한 부분들은 디스플레이 산업 및 기술이 지향하는 대면적, 저가격, 공정의 단순함을 해 결해 줄 수 있기 때문에 최근 투명박막 트랜지스터에 관 한 연구가 급증하고 있다. $\mathrm{GaN}$, 다이아몬드 등과 같은 투명박막 트랜지스터들은 이미 알려져 있지만, 이들은 재 료비와 생산비 등 원가가 비싸서 디스플레이 등 비교적

Corresponding author

E-Mail : jmmyoung@yonsei.ac.kr (J. M. Myoung)
대형 스크린이 필요한 투명 전자 부품에는 사용할 수 없 다는 단점이 있는 반면, 산화물 박막트랜지스터는 유리, 금속, 플라스틱 등등 그 기판 종류에 상관없이 균일한 제 작이 가능하며, 상온 및 저온에서 제작 가능하고, 저렴 한 비용으로 제작 가능하다는 장점 때문에 산화물을 기 반으로 하는 박막트랜지스터 연구가 많이 이루어지고 있 다. ${ }^{1-8)}$

현재 박막트랜지스터 물질로 많이 연구되고 있는 산화 물은 $\mathrm{ZnO}(3.4 \mathrm{eV})^{9)}$ 나 $\mathrm{InO}_{\mathrm{x}}(3.6 \mathrm{eV})^{10)}, \mathrm{GaO}_{\mathrm{x}}(4.9 \mathrm{eV})^{11)}$, $\mathrm{SnO}_{\mathrm{x}}(3.7 \mathrm{eV})^{12)}$ 등의 물질과 각각의 조합으로 구성된 재 료들이 주로 사용되고 있다. ${ }^{13-18)}$ 가장 많은 연구가 이루어 진 $\mathrm{ZnO}$ 기반의 박막트랜지스터는 전자 이동도와 switching 속도에서 우수한 특성을 보이나, 비정질 $\mathrm{ZnO}$ 기반의 박 막트랜지스터의 경우 트랜지스터의 안정성이 떨어지는 것 으로 보고되고 있다. ${ }^{19)}$ 그러나 $\mathrm{IGZO}$ 물질의 경우, 유독 성이 낮으며, 높은 전자 이동도의 특성을 가지고 있으며, 다성분계이기 때문에 통상적인 박막 성장 조건에서 비정 질 구조로 제작 가능하다. ${ }^{18)}$ 
따라서 본 연구에서는 $\mathrm{ZnO}$ 보다 넓은 밴드갭 에너지 를 가질 수 있으며, n-type 특성을 보이고, 비정질 구조 로 제작 가능한 $\mathrm{IGZO}$ 물질로 DC 마그네트론 스퍼터를 이용하여 상온에서 박막트랜지스터를 제작하였으며, 열처 리를 통해서 열처리 이전과 이후의 특성 변화를 분석하 였다.

\section{2. 실험 방법}

IGZO 박막은 DC 마그네트론 스퍼터링 방법을 이용 하여 상온에서 유리 기판과 $\mathrm{SiO}_{2}$ 가 $300 \mathrm{~nm}$ 증착된 $\mathrm{p}^{++}$ $\mathrm{Si}$ (100) 기판 위에 각각 증착하였다. 기판은 $\mathrm{TCE}-$ 아세 톤-메탄올에서 각각 15 분씩 초음파 세척을 하고, 탈이온 수로 헹군 뒤 $\mathrm{N}_{2}$ 가스로 기판의 수분을 제거하였다. 박 막 증착시 초기 진공은 $\sim 10^{-3} \mathrm{~Pa}$ 이었으며, 상온에서 $\mathrm{DC}$ 스퍼터 챔버 안에 $\mathrm{Ar}$ 가스를 $5 \mathrm{sccm}$ 유입시킨 후 0.67 $\mathrm{Pa}$ 의 작업 진공으로 유지시켜 IGZO 타겟의 power를 20 $\mathrm{W}$ 로 하여 20분간 pre-스퍼터링 한 후, 증착하였다.

투명트랜지스터 물질로서 IGZO 박막의 적합성 여부를 확인하기 위하여 bottom 게이트 구조로 DC 마그네트론 스퍼터링 방법을 이용하여 박막트랜지스터를 제작하였다. 전극 증착시 초기 진공은 $\sim 10^{-3} \mathrm{~Pa}$ 이었으며, 상온에서 $\mathrm{DC}$ 스퍼터 챔버 안에 $\mathrm{Ar}$ 가스를 $5 \mathrm{sccm}$ 유입시킨 후 0.39 $\mathrm{Pa}$ 의 작업 진공으로 유지시켜 $\mathrm{Ti}$ 타겟의 power를 $30 \mathrm{~W}$, $\mathrm{Au}$ 타겟의 power를 $10 \mathrm{~W}$ 로 하여 pre-스퍼터링 한 후, $\mathrm{IGZO}$ 박막위에 double layer로 증착하였다. 증착된 박막 의 열처리에 따른 특성 변화를 분석하고자 수평로를 이 용하여 대기 분위기로 $300{ }^{\circ} \mathrm{C}$ 에서 1 시간 동안 열처리를 하였다.

Field emission scanning electron microscope (FESEM) 을 통해 IGZO 박막의 표면의 형상과 두께를 확인하였 으며, X-ray diffraction (XRD) 분석을 통해 IGZO 박막 의 결정학적 특성을 관찰하였다. I-V 분석을 통해 $\mathrm{IGZO}$ 박막의 전기적 특성을 관찰하였으며, UV-VIS를 이용하 여 IGZO 박막의 투과율을 분석하여 투명트랜지스터로의 응용 가능성을 확인하였다.

\section{3. 결과 및 고찰}

Fig. 1은 DC 마그네트론 스퍼터를 이용하여 IGZO 타 겟 power $20 \mathrm{~W}$ 에서 증착한 IGZO 박막의 열처리하기 전과 열처리 이후의 박막 표면 형상을 $\mathrm{FESEM}$ 으로 $45^{\circ}$ 경사에서 관찰한 것이다. Fig. 1의 FESEM 사진을 통해 열처리하기 전의 IGZO 박막의 표면 형상은 비정질 구 조의 박막에서 확인할 수 있는 표면 형상과 같이 평탄 한 것을 알 수 있었다. 열처리 전과 열처리 후를 비교 했을 때 박막의 표면 형상은 열처리 전 박막이 열처리
이후의 박막보다 표면 형상이 평탄한 것을 알 수 있었 다. 또한 열처리 전과 열처리 후의 박막의 두께는 $50 \mathrm{~nm}$ 에서 $45 \mathrm{~nm}$ 로 감소되었음을 확인할 수 있었다. 이는 열 처리 시 IGZO 박막 내 격자 재배열이 일어나면서 공 공이 감소함에 따라 조밀한 구조를 가지게 되기 때문인 것으로 판단된다.

Fig. 2는 DC 마그네트론 스퍼터를 이용하여 IGZO 타 겟 power $20 \mathrm{~W}$ 에서 증착한 $\mathrm{IGZO}$ 박막의 열처리하기 전과 열처리 한 후의 결정학적 특성을 $\mathrm{XRD}$ 로 관찰한 것이다. 상온에서 증착된 $\mathrm{IGZO}$ 박막은 비정질 구조를 가 지는 것을 확인할 수 있었다. 수평로에서 열처리한 후 $\mathrm{IGZO}$ 박막의 결정학적 특성은 열처리 이전과 비교해서 비정질 면의 peak 세기가 감소하였으나 열처리 전과 동 일한 비정질 구조인 것을 관찰하였다. 이러한 결과는 $\mathrm{IGZO}$ 박막의 결정구조는 비정질의 특성을 보이지만 열 처리에 따라 박막 내 비정질 면이 감소한다는 것을 의 미하며 Fig. 1의 FESEM 사진에서 볼 수 있었던 박막 의 표면 형상 변화와도 일치한다.

Fig. 3(a)와 (b)는 증착한 IGZO 박막 위에 bottom gate 구조로 트랜지스터를 제작한 뒤 측정한 전기적 특 성 결과이다. Fig. $3(\mathrm{a})$ 는 $300 \mathrm{~nm}$ 의 $\mathrm{SiO}_{2}$ 가 게이트 유전 막인 $\mathrm{IGZO}$ 박막트랜지스터의 $\mathrm{I}_{\mathrm{DS}}-\mathrm{V}_{\mathrm{DS}}$ 결과이다. 제작된 $\mathrm{IGZO}$ 박막트랜지스터가 게이트 $\mathrm{V}_{\mathrm{G}}$ 가 0 일 때, 낮은 drain 전류에 의해 enhancement mode로 동작되는 것을 보여
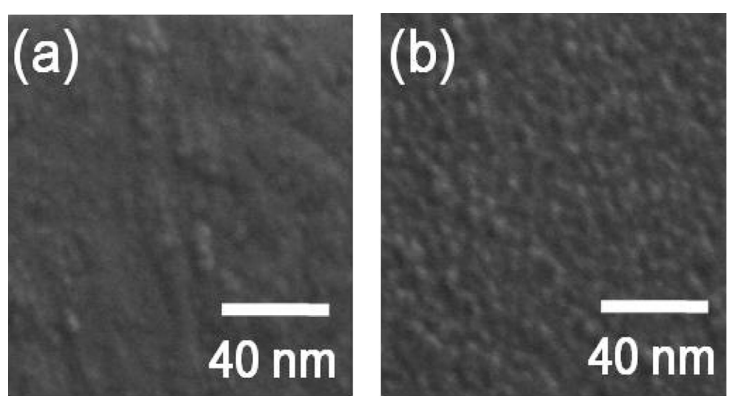

Fig. 1. FESEM images (with an apparent viewing angle of $\left.45^{\circ}\right)$ of the (a) non-annealed and (b) annealed IGZO thin films.

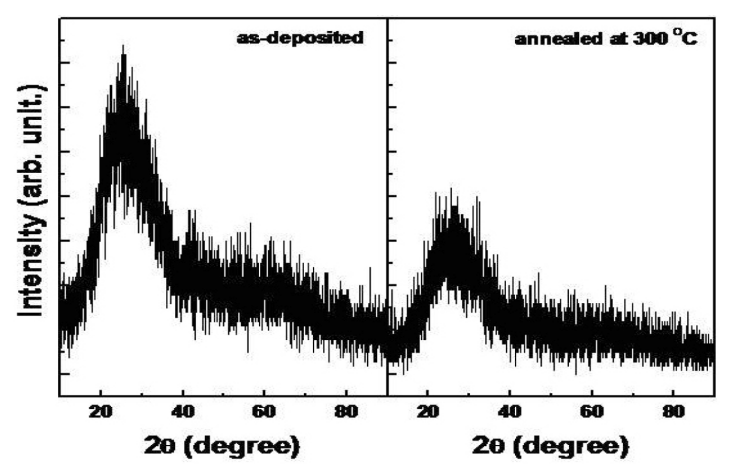

Fig. 2. XRD spectra of non-annealed and annealed IGZO thin films. 

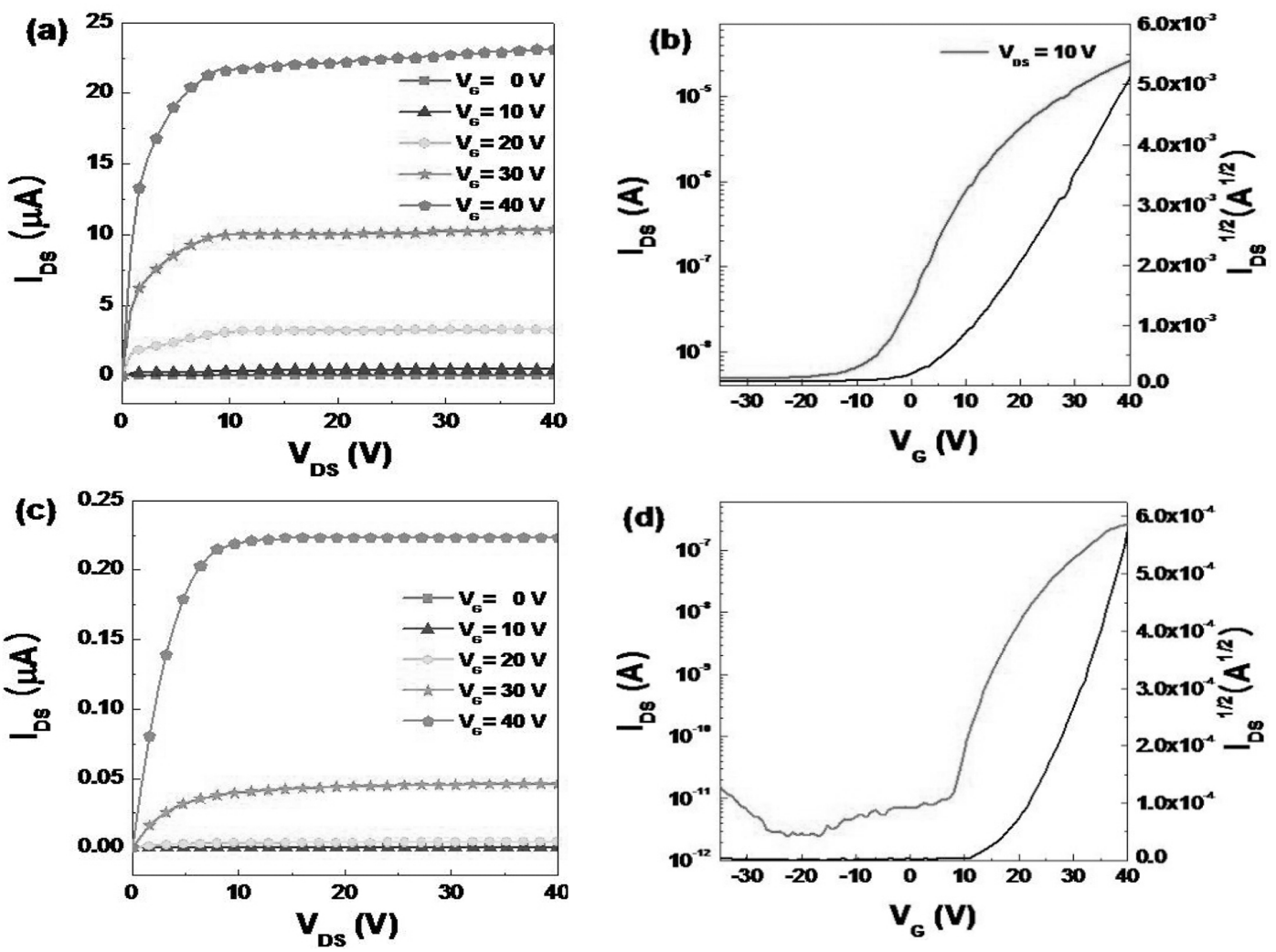

Fig. 3. Typical IGZO TFT characteristics with the channel size of $200 \times 1000 \mu \mathrm{m}^{2}$ as a length and a width; (a) Output characteristics of the non-annealed IGZO TFT, (b) Transfer characteristics of the non-annealed IGZO TFT at $V_{D S}=10 \mathrm{~V}$, (c) Output characteristics of the annealed IGZO TFT, (d) Transfer characteristics of the annealed IGZO TFT at $\mathrm{V}_{\mathrm{DS}}=10 \mathrm{~V}$.

주며, saturation 전류는 $\mathrm{V}_{\mathrm{G}}$ 가 $40 \mathrm{~V}$ 일 때, $21 \mu \mathrm{A}$ 였다. Fig. $3(\mathrm{~b})$ 는 $300 \mathrm{~nm}$ 의 $\mathrm{SiO}_{2}$ 가 게이트 유전막인 IGZO 박 막트랜지스터의 transfer 특성으로서 $\mathrm{V}_{\mathrm{DS}}$ 를 $10 \mathrm{~V}$ 로 고정 시켰을 때, $\mathrm{V}_{\mathrm{G}}$ 에 대한 $\mathrm{I}_{\mathrm{DS}}$ 와 $\mathrm{I}_{\mathrm{DS}}{ }^{1 / 2}$ 결과이다. 제작된 $\mathrm{IGZO}$ 박막의 saturation 이동도 $\mu_{\mathrm{sat}}$ 와 threshold 전압 $\mathrm{V}_{\mathrm{TH}}$ 는 다음 식에 의해 표현된다. ${ }^{20)}$

$$
\mathrm{I}_{\mathrm{DS}}=\left(\frac{\mu_{\mathrm{sat}} \mathrm{WC}_{\mathrm{i}}}{2 \mathrm{~L}}\right)\left(\mathrm{V}_{\mathrm{GS}}-\mathrm{V}_{\mathrm{TH}}\right)^{2}
$$

Saturation 영역에 대해 $\mathrm{C}_{\mathrm{i}}$ 는 게이트 절연막의 단위 면 적당 capacitance, $\mathrm{W}$ 는 channel 층의 넓이, $\mathrm{L}$ 은 channel 층의 길이를 의미한다. Fig. 3(a)와 (b)에서 볼 수 있듯 이, IGZO 박막트랜지스터의 $\mathrm{V}_{\mathrm{DS}}$ 를 $10 \mathrm{~V}$ 로 고정시켰을 때, drain 전류의 on-off 비는 $~ 10^{4}$ 이었으며, $\mathrm{V}_{\mathrm{TH}}=1.46$ $\mathrm{V}, \mu_{\mathrm{sat}}=4.92 \times 10^{-1} \mathrm{~cm}^{2} / \mathrm{V} \cdot \mathrm{s}$ 였다.

Fig. 3(c)와 (d)는 증착한 IGZO 박막 위에 bottom gate 구조로 트랜지스터를 제작한 뒤 $300{ }^{\circ} \mathrm{C}$ 에서 1 시간 동안 열처리한 후 측정한 전기적 특성 결과이다. Fig. $3(\mathrm{c})$ 는 $300{ }^{\circ} \mathrm{C}$ 에서 1 시간동안 열처리한 후 IGZO 박막트 랜지스터의 $\mathrm{I}_{\mathrm{DS}}-\mathrm{V}_{\mathrm{DS}}$ 결과이다. 제작된 $\mathrm{IGZO}$ 박막트랜지 스터가 게이트 $\mathrm{V}_{\mathrm{G}}$ 가 0 일 때, 낮은 drain 전류에 의해

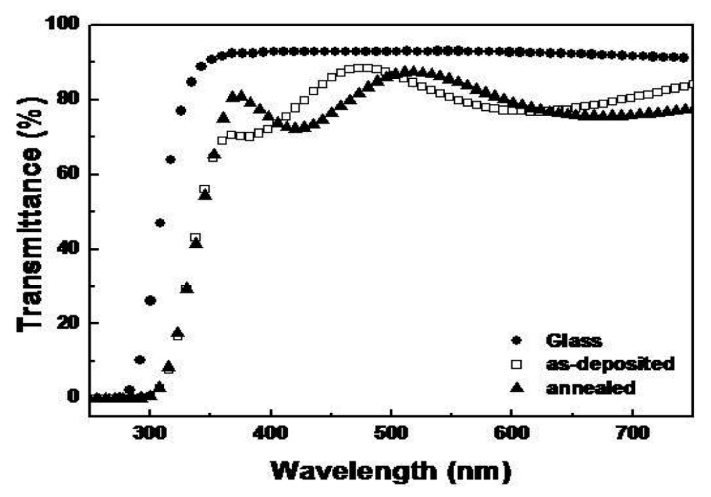

Fig. 4. Optical transmittance of non-annealed and annealed IGZO thin films.

enhancement mode로 동작되는 것을 보여주며, saturation 전류는 $\mathrm{V}_{\mathrm{G}}$ 가 $40 \mathrm{~V}$ 일 때, $0.219 \mu \mathrm{A}$ 였다. Fig. $3(\mathrm{~d})$ 는 $300^{\circ} \mathrm{C}$ 에서 1시간동안 열처리한 후 IGZO 박막트랜지스터의 transfer 특성으로서 $\mathrm{V}_{\mathrm{DS}}$ 를 $10 \mathrm{~V}$ 로 고정시켰을 때, $\mathrm{V}_{\mathrm{G}}$ 에 대한 $\mathrm{I}_{\mathrm{DS}}$ 와 $\mathrm{I}_{\mathrm{DS}}{ }^{1 / 2}$ 결과이다. Fig. 3(c)와 (d)에서 볼 수 있듯이, IGZO 박막트랜지스터의 $\mathrm{V}_{\mathrm{DS}}$ 를 $10 \mathrm{~V}$ 로 고정시 켰을 때, drain 전류의 on-off 비는 $~ 10^{4}$ 이었으며, $\mathrm{V}_{\mathrm{TH}}=$ $15.43 \mathrm{~V}, \mu_{\mathrm{sat}}=1.49 \times 10^{-1} \mathrm{~cm}^{2} / \mathrm{V} \cdot \mathrm{s}$ 였다. IGZO 박막트랜 
지스터의 열처리 전과 열처리 이후의 전기적 특성을 비 교하면 열처리 이전의 트랜지스터의 특성이 더 우수함을 알 수 있다. 이는 열처리 이후의 박막의 표면 거칠기가 증가함에 따라 scattering이 증가하여 channel 층의 전자 이동도가 감소하였기 때문인 것으로 판단된다.

IGZO 박막의 투명트랜지스터로의 적합성을 확인하기 위하여 유리 기판에 증착한 뒤 투과도를 평가하였다. Fig. 4는 IGZO 박막의 열처리 전과 열처리 이후의 광학적 특 성을 관찰한 결과이다. Fig. 4에서 볼 수 있듯이 박막의 열처리 전과 열처리 이후의 밴드갭 에너지는 크게 차이 가 없으며, 투과도의 경우 열처리 이후의 박막이 조금 더 우수한 것을 확인할 수 있다. 이는 열처리를 통해 IGZO 박막 내 $\mathrm{O}_{2}$ 관련 결함들이 감소하였기 때문으로 보여지 며, 열처리 이전과 이후의 IGZO 박막 모두 유리 기판 과 비교했을 때, $80 \%$ 이상의 우수한 투과율을 보이는 것을 확인할 수 있었다.

\section{4. 결 론}

$\mathrm{DC}$ 마그네트론 스퍼터링 방법을 이용하여 상온에서 20 $\mathrm{W}$ 의 power로 증착한 IGZO 박막은 표면 형상 및 결정 학적 특성이 비정질에 가까운 것을 $\mathrm{FESEM}$ 과 XRD 결 과를 통해 확인할 수 있었으며, 열처리 이전과 이후를 비 교하면 열처리 이전의 박막이 비정질 특성이 좀 더 강 한 것을 확인할 수 있었다. 박막트랜지스터로서의 특성 을 확인하기 위하여 bottom gate 구조로 트랜지스터를 제 작하여 특성을 평가한 결과, 열처리 이전의 트랜지스터 는 $\mu_{\mathrm{sat}}=4.92 \times 10^{-1} \mathrm{~cm}^{2} / \mathrm{V} \cdot \mathrm{s}$, 열처리 이후의 트랜지스터 는 $\mu_{\mathrm{sat}}=1.49 \times 10^{-1} \mathrm{~cm}^{2} / \mathrm{V} \cdot \mathrm{s}$ 의 전자이동도를 가지는 것 을 확인하였다. IGZO 박막의 투과도를 관찰한 결과, 열 처리 이전과 열처리 이후의 박막 모두 유리 기판과 비 교하여 $80 \%$ 이상의 우수한 투과율을 보임으로서 투명 트랜지스터 제작에 적합함을 확인할 수 있었다.

\section{감사의 글}

이 논문은 LG Display 산학연구프로그램 및 $\mathrm{BK} 21$ 사업의 지원을 받아 수행된 연구임.

\section{참 고 문 헌}

1. E. Fortunato, P. Barquinha, A. Pimentel, A. Gonçalves, A. Marques, L. Pereira, and R. Martins, Thin Solid Films, 487, 205 (2005).
2. H. Hosono, Thin Solid Films, 515, 6000 (2007).

3. K. Nomura, H. Ohta, K. Ueda, T. Kamiya, M. Hirano, and H. Hosono, Science, 300, 1269 (2003).

4. R.L. Hoffman, B.J. Norris, and J.F. Wager, Appl. Phys. Lett., 82, 733 (2003).

5. R. Martins, P. Almeida, P. Barquinha, L. Pereira, I. Ferreira and E. Fortunato, J. Non. Cryst. Solids, 352, 1471 (2006).

6. H. Yabuta, M. Sano, K. Abe, T. Aiba, T. Den, H. Kumomi, K. Nomura, T. Kamiya and H. Hosono, Appl. Phys. Lett., 89, 112123 (2006).

7. E. Fortunato, P.M.C. Barquinha, A.C.M.B.G. Pimentel, A.M.F. Gonçalves, A.J.S. Marques, L.M.N. Pereira and R. Martins, Adv. Mater., 17, 590 (2005).

8. C. J. Kim, D. H. Kang, I. H. Song, J. C. Park, H. Lim, S. I. Kim, B. H. Lee, R. J. Chung, J. C. Lee, and Y. S. Park, IEDM Tech. Dig, 11.6.1 (2006).

9. H. Q. Chiang, J. F. Wager, R. L. Hoffman, J. Jeong, and D. A. Keszler, Appl. Phys. Lett., 86, 013503 (2005).

10. G. Lavareda, C. Nunes de Carvalho, E. Fortunato, A.R. Ramos, E. Alves, O. Conde and A. Amaral, J. Non-Cryst. Solids, 352, 2311 (2006).

11. K. Matsuzaki, H. Hiramatsu, K. Nomura, H. Yanagi, T. Kamiya, M. Hiranob, and H. Hosono, Thin Solid Films, 496, 37 (2006).

12. R. E. Presley, C. L. Munsee, C.-H. Park, J. F. Wager, and D. A. Keszler, J. Phys. D: Appl. Phys., 37, 2810, (2004)

13. G. Hu, B. Kumar, H. Gong, E. F. Chor, and P. Wu, Appl. Phys. Lett., 88, 101901 (2006).

14. H. Jeon, V. P. Verma, S. Hwang, S. Lee, C. Park, D. H. Kim, W. Choi, and M. Jeon, Jpn. J. Appl. Phys., 47, 87 (2008).

15. W. Lim, Y. L. Wang, F. Ren, D. P. Norton, I. I. Kravchenko, J. M. Zavada, and S. J. Pearton, Appl. Surf. Sci., 254, 2828 (2008).

16. D. Hong, H. Q. Chiang, and J. F. Wager, J. Vac. Sci. Technol. B, 24, L23 (2006).

17. J. K. Jeong, M. Kim, J. H. Jeong, H. J. Lee, T. K. Ahn, H. S. Shin, K. Y. Kang, H. Seo, J. S. Park, H. Yang, H. J. Chung, Y. G. Mo and H. D. Kim, IMID Digest, 145 (2007).

18. A. Suresh, P. Gollakota, P. Wellenius, A. Dhawan, and J.F. Muth, Thin Solid Films, 516, 1326 (2008).

19. H. Kumomi, K. Nomura, T. Kamiya, and H. Hosono, Thin Solid Films, 516, 1516 (2008).

20. W. Lim, S. Kim, Y.-L. Wang, J. W. Lee, D.P. Norton, S. J. Pearton, F. Ren, and I. I. Kravchenko J. Electrochem. Soc., 155, H383 (2008). 